\title{
Comparison of Effects of PELD and Fenestration in the Treatment of Geriatric Lumbar Lateral Recess Stenosis
}

This article was published in the following Dove Press journal: Clinical Interventions in Aging

\section{Zhendong Lv* \\ Linyu Jin* \\ Kun Wang (iD) \\ Zhi Chen \\ Fengning $\mathrm{Li}$ \\ Yuhui Zhang \\ Lifeng Lao \\ Chun Zhou \\ Xinfeng Li \\ Hongxing Shen}

Department of Spine Surgery, Renji Hospital, School of Medicine, Shanghai Jiao Tong University, Shanghai, People's Republic of China

*These authors contributed equally to this work
Correspondence: Xinfeng Li; Hongxing Shen No. 160 Pujian Road, Shanghai 200 I27, People's Republic of China

Tel +86- $883599 \mid 449$;

$+86-13601814912$

Fax +86-021-58395057

Email Ixfrenji@I26.com;

shenhxgk@I26.com
Purpose: Although degenerative lumbar spinal stenosis (LSS) is increasingly being diagnosed in older people, there is much uncertainty about the appropriate operative treatment options. The objective of this study was to compare the outcome of percutaneous endoscopic lumbar decompression (PELD) versus fenestration for lumbar lateral recess stenosis (LRS) in geriatric patients over 75 years old.

Materials and methods: This prospective controlled study was performed on 46 consecutive over aged patients with lateral recess stenosis who underwent either PELD or fenestration. Clinical data were recorded before, 1 week, 3 months and 1.5 years after surgery using visual analog scale (VAS), Japanese Orthopaedic Association Score (JOA), The Short-Form-36 (SF-36), and the modified Macnab evaluation criteria.

Results: The patients' mean age was 82.7 years (aged 75-93 years) in PELD group and 79.1 years (aged 75-88 years) in fenestration group. No statistical difference was found between PELD group and fenestration group with regards to VAS-back pain, VAS-leg pain, JOA and at 3 months and 1.5-year follow-up. However, the PELD group had a lower mean VAS for back pain at 1 week postoperatively $(\mathrm{P}<0.05)$. The quality of life in PELD group achieved the same remarkable improvement as fenestration group $(\mathrm{P}>0.05)$. Operative time (min) was similar between two groups $(p>0.05)$, while the PELD techniques brought advantages in blood loss (mL) (48.3 vs 128.2, p<0.05), early ambulation (h) (5.5 vs 25.2, $\mathrm{p}<0.05$ ), and anesthesia-related complications.

Conclusion: Both PELD and fenestration showed favorable clinical outcomes for the treatment of lumbar lateral recess stenosis. In addition, PELD had advantages such as reduced traumatization and less anesthesia-related complications. In terms of quality of life and complications after operation, PELD under local anesthesia could be an efficient supplement to conventional decompression surgery in geriatric patients with lumbar lateral recess stenosis.

Keywords: geriatric patients, lumbar lateral recess stenosis, percutaneous endoscopic lumbar decompression, PELD, minimally invasive

\section{Introduction}

Degenerative lumbar spinal stenosis (DLSS) is caused by degenerative changes of the intervertebral disc, facet joints or ligaments, which primarily affect the elderly population. ${ }^{1,2}$ The clinical manifestations are frequently reported as neurogenic intermittent claudication or sciatica with or without low back pain ${ }^{3}$ resulting in a much stronger negative impact on health-related quality of life. ${ }^{4}$ With aging of the population, orthopedists are now increasingly confronted with lumbar spinal 
stenosis in the elderly. These elderly patients usually have a long history of pain and dysfunction, poor conservative treatment results, and severe symptoms since lumbar spinal stenosis is a slowly progressive degenerative process which deteriorates with aging. ${ }^{5}$

Symptomatic patients with ineffective conservative treatment require surgical treatment. Conventional laminectomy is effective. However, it involves removal of the dorsal structure of spine and is thus considered to promote iatrogenic instability. ${ }^{6}$ Meanwhile, it requires internal fixation and fusion which could be associated with increased risks of major complications (e.g., acute myocardial infarct, respiratory failure, pneumonia), higher infection rates, and internal fixation failure (e.g., screw loosening and cage sinking) in the elderly. ${ }^{7}$

Fenestration, also referred to as laminotomy, was described by Kida et al in 1980 in Japan and Getty et $\mathrm{al}^{8}$ in 1981 in the United Kingdom. It involves partial undercutting facetectomy and partial laminectomy and can preserve spinal stability without instrumented spinal fusion by maintaining posterior ligamentous complex. ${ }^{8}$ Encouraging results of this less-invasive decompression for lumbar spinal stenosis have been reported by various authors. ${ }^{9-11}$ Nowadays, fenestration is widely performed by many surgeons and is favored as an alternative to laminectomy. ${ }^{12}$ Nevertheless, for elderly patients with systemic comorbidities, conducting fenestration under general anesthesia can still be a challenge.

In the past decade, minimally invasive surgery has developed rapidly. With the improvements in surgical techniques, optical equipment and surgical instruments, the cutting edge of spinal endoscopy of PELD has shifted from treatment of soft disc herniation to management of osseous lumbar spinal stenosis. ${ }^{13-15}$ Although high surgical satisfaction rates have been reported in some literature, ${ }^{13,15}$ the technique is still controversial in the treatment of lumbar spinal stenosis due to low quality of the studies ${ }^{16}$ and relatively limited range of decompression of endoscope interventions.

At present, there appears to be a trend away from more aggressive (laminectomy) to more selective techniques since decompression surgery plus fusion surgery may not result in better clinical outcomes than decompression operation alone for treatment of lumbar spinal stenosis. ${ }^{17}$ Therefore, we report a 1.5-year prospective follow-up study comparing the effects of two stability-preserving decompression techniques, PELD with twice foraminoplasty and fenestration, for the surgical treatment of lumbar lateral recess stenosis in the elderly (over 75 years old).

\section{Materials and Methods}

\section{Participants}

This prospective study was conducted involving 46 consecutive patients undergoing lumbar decompression surgery at a single institution between October 2015 to March 2017. All the participants provided written informed consent to participate in the study. This study was approved by the ethics review boards of Shanghai Renji Hospital and was performed in accordance with the Declaration of Helsinki.

Patients who were scheduled to undergo lumbar decompression surgery with a history of predominant unilateral leg pain and lumbar recess stenosis verified by magnetic resonance imaging (MRI) or computed tomography (CT) were eligible. Single-level decompression was included. Flexion-extension radiographic views were used for determining radiographic instability. Nerve block was used to help in determining the interest segment. Since the main benefit of these two decompressive operations was to relieve pain of "root" origin and the cause of low back pain was varied in each individual patient, patients were firmly told that the relief of back pain after decompression was a bonus. All operations were completed by one surgeon with more than 5 years surgical experience.

The patients were assigned randomly to fenestration group (Group 1) or PELD group (Group 2) at ratio of 1:1 and were selected to compared with the inclusion criteria:

1. 75 years of age or older;

2. a diagnosis of predominant foraminal/lateral recess stenosis based on clinical history, physical examination and imaging studies such as CT or MRI;

3. clinical syndrome predominantly characterized by unilateral lumbar radicular symptoms (lower extremity pain, numbness or intermittent claudication) without severe back pain;

4. failure of nonoperative treatment for at least 6 months and disabling lifestyle alteration.

And the exclusion criteria:

1. lumbar instability in dynamic radiographs: translation greater than $3 \mathrm{~mm}$ or changes in angulation greater than $10^{\circ}$ at 1 motion segment on the lateral flexion and extension;

2. pathological conditions such as lumbar infection, tumor or fracture;

3. a history of previous lumbar surgery. 


\section{Surgical Procedure}

Group 1 patients underwent decompression operation by fenestration technique as previously described. ${ }^{8,18}$ In brief, a posterior midline incision was made centered over the spinal level of interest. Then the paravertebral muscles were split and retracted laterally to the outer edge of the facet joint. Next, medial undercutting facetectomy was performed followed by removing of adjacent lamina margin and its ligamentum flavum. A minimum of $50 \%$ of the structure of a facet joint should be preserved to prevent iatrogenic spinal instability finally.

For Group 2, a $0.8 \mathrm{~cm}$ incision was made $12-14 \mathrm{~cm}$ from the posterior middle line which is farther than the distance of a typical transforaminal approach for the convenience of dorsal decompression. Then the foraminoplasty was performed by cutting off anterior lateral of superior articular process (SAP). After placing the working cannula along the guide wire, a secondary extended foraminoplasty was conducted by removing ventral inferior portion of the SAP. Finally, a full-scale nerve root decompression was accomplished by removing the hypertrophied facet joints and ligamentum flavum on the dorsal side and hypertrophied posterior longitudinal ligaments (PLL), extruded disc material and osteophytes on the ventral side until the nerve showed pulsations with the heart rate.

Group 1's procedure was performed after induction of general anesthesia, while Group 2's was conducted under local anesthesia. Both groups received intravenous flurbiprofen axetil $(50 \mathrm{mg})$ daily for postoperative analgesia.

\section{Clinical Evaluation and Follow-Up}

Neurological function and pain status were evaluated using the Japanese Orthopaedic Association Score (JOA) and visual analog scale (VAS, the lowest, 0 , represents "no pain" and the highest, 10, represents "worst pain imaginable") preoperatively and at 1 week, 3 months, 1.5 years postoperatively. In addition, surgical satisfaction rates were assessed by using the modified Macnab evaluation criteria and health-related quality of life was measured with 36-Item Short Form Health Survey (SF-36) at the final follow-up.

\section{Sample Size}

We calculated that a minimum of 20 patients in each group would be required for the trial to have $80 \%$ power to detect a difference in the VAS for leg pain (primary outcome measures) of at least 1.6 between the treatment groups at a significance level of 0.05 . We chose a difference of 1.6 since a decrease in the VAS for the leg pain score of $1.6 \mathrm{had}$ been reported in previous literature to indicate minimal clinically important difference after lumbar spine surgery. ${ }^{19} \mathrm{On}$ the assumption of $15 \%$ rate of loss to follow-up, the randomization was stopped at 46 patients, since more than 20 patients would have been included in each group.

\section{Statistical Analysis}

Statistical analyses were performed with SPSS software (SPSS Inc, Chicago, IL, USA). Paired $t$-test and independent samples $t$-test were applied for the comparison of the clinical results in the PELD group and fenestration group. Enumeration data were analyzed using chi-squared test. A value of $\mathrm{P}<0.05$ was considered significant.

\section{Results}

We kept in contact with a total of 45 patients (22 in fenestration group and 23 in PELD group) throughout the follow-up. The follow-up rate was $97.8 \%$ since 1 patient in fenestration group died of a myocardial infarction in the first year of follow-up. Demographic data were summarized in Table 1. Baseline characteristics were remarkably similar in the two groups.

Table I Patient Demographics and Operative Characteristics in PELD Group and Fenestration Group

\begin{tabular}{|l|l|l|l|}
\hline Characteristic & PELD & Fenestration & P \\
\hline Age (y), mean (range) & $82.7(75-93)$ & $79.1(75-88)$ & 0.435 \\
\hline $\begin{array}{l}\text { Gender (n/\%) } \\
\text { Female } \\
\text { Male }\end{array}$ & $10(43.5)$ & $10(45.5)$ & 0.894 \\
\hline BMI & $13(56.5)$ & $12(54.5)$ & \\
\hline $\begin{array}{l}\text { Operative level } \\
\text { L3/4 }\end{array}$ & $23.2 \pm 4.2$ & $25.4 \pm 5.3$ & 0.593 \\
L4/5 & 2 & & 0.699 \\
L5/SI & 12 & 1 & \\
\hline Comorbid diseases (n/\%) & 9 & 14 & \\
Hypertension & $13(56.5)$ & $10(45.5)$ & \\
Diabetes mellitus & $5(21.7)$ & $6(27.3)$ & \\
Heart disease & $8(34.8)$ & $6(27.3)$ & \\
Cerebrovascular infarction & $2(8.7)$ & $3(13.6)$ & \\
Respiratory diseases & $4(17.4)$ & $2(9.1)$ & \\
Renal/Ureteral disease & $3(13.0)$ & $2(9.1)$ & \\
Peripheral vascular disease & $2(8.7)$ & $2(9.1)$ & \\
Neoplasia & $2(8.7)$ & $1(4.5)$ & \\
Anxiety neurosis & $1(4.3)$ & $0(0.0)$ & \\
Mean number of comorbid & 1.7 & 1.5 & \\
diseases & & & \\
\hline
\end{tabular}


Perioperative data, including operative time, blood loss, time until ambulation, and hospital stay time were recorded. No significant between-group differences were found in operative time ( $\mathrm{P}>0.05)$. However, PELD had advantages in blood loss (mL) (48.3 vs 128.2, $\mathrm{p}<0.05$ ), early ambulation (h) (5.5 vs $25.2, \mathrm{p}<0.05)$, and hospitalization (d) (2.2 vs $4.3, \mathrm{p}<0.05$ ) (Table 2).

The trends in VAS scores and JOA in PELD group were similar to those in the fenestration group (Figure 1). No significant difference in the mean VAS for back pain, VAS for leg pain and JOA scores was found between these groups preoperatively and at 3 months and 18 months after surgery, while VAS for back pain in PELD group was superior to that in fenestration group at 1 week after surgery $(3.7 \pm 0.7$ vs $4.5 \pm 0.9,<0.05)$. In addition, we found a similar long-lasting improvement in quality of life after both PELD and fenestration in the majority of patients (Figure 2). The outcomes of modified Macnab criteria were shown in Figure 3. Good-to-excellent rate was $82.6 \%$ in PELD group and $86.4 \%$ in fenestration group at the final review.

With regard to complications, there was 1 case of dural tear during nerve decompression in each group. In the PELD group, the dural lesion was covered with a dural graft matrix without a suture after decompressive manipulation and stopping the irrigation. Primary suturing was conducted to repair dura in the fenestration group. In addition, 2 cases of postoperative delirium were observed for several days but were fully reversible in fenestration group.

A thorough nerve root decompression, by removing the dorsal partial hypertrophied facet joint and ligament flavum and ventral extruded disc, was displayed on crosssectional CT or MRI films (Figures 4 and 5).

Table 2 General Clinical Results in the PELD Group and Fenestration Group

\begin{tabular}{|l|l|l|l|}
\hline $\begin{array}{l}\text { Outcome } \\
\text { Measure }\end{array}$ & $\begin{array}{l}\text { PELD (n=23), } \\
\text { Mean (Range) }\end{array}$ & $\begin{array}{l}\text { Fenestration } \\
(\mathbf{n = 2 2}), \text { Mean } \\
\text { (Range) }\end{array}$ & $\mathbf{p}$ \\
\hline $\begin{array}{l}\text { Operative time } \\
(\mathrm{min})\end{array}$ & $65.7(45.0-85.0)$ & $61.8(50.0-75.0)$ & 0.196 \\
\hline $\begin{array}{l}\text { Bleeding quantity } \\
(\mathrm{mL})\end{array}$ & $48.3(40.0-60.0)$ & $128.2(95.0-150.0)$ & $<0.05$ \\
\hline Length of stay (d) & $2.2(1.0-3.0)$ & $4.3(3.0-6.0)$ & $<0.05$ \\
\hline $\begin{array}{l}\text { Hours until } \\
\text { ambulation (h) }\end{array}$ & $5.5(2.0-12.0)$ & $25.2(20.0-38.0)$ & $<0.05$ \\
\hline
\end{tabular}

\section{Discussion}

A one and a half-year follow-up was conducted to evaluate and compare the safety and curative effect of PELD and fenestration in geriatric patients with lumber recess stenosis. From this research, we found that patients suffered hugely with regard to pain, function and quality of life in both groups. Although no significant difference was found in clinical results between PELD and fenestration groups, the PELD techniques brought advantages in terms of less trauma, faster recovery, and less postoperative anesthesia-related complications from our own experience.

Anatomically, the spinal canal consists of two main regions, central and nerve root canal. The latter is a funnelshaped tunnel in which the nerve root travels downwards and laterally from the lateral aspect of the dural sac, and connects the intraspinal space and the extraspinal space. Vital et $\mathrm{al}^{20}$ divided the nerve root canal into retrodiscal, parapedicular (the lateral recess per se), and foraminal part. Similarly, Lee et $\mathrm{al}^{21}$ classified the lateral lumber spinal canal into three zones: entrance zone, mid zone, and exit zone. This lateral area of the spinal canal is subjected to pathological alterations. Various stenotic lesions at any site of it can cause radicular symptoms such as lower extremity pain, paresthesia or intermittent claudication. Therefore, it is very important to identify the sites and factors (osseous and/ or soft tissue elements) of nerve root compression before the operation.

The goal of the operation is to decompress the "incarcerated" nerve root, and one of the major causes of surgical failure is represented by the residual radicular pain as well which is usually induced by remnants left around the nerve root. In order to complete full course of the entire traversing nerve root, the anatomic limitation at foramen must be broken. In our study, accordingly, a secondary foraminoplasty, undercutting of the ventral inferior portion of the SAP, was performed in addition to the anterior lateral removal of the upper articular process, which allowed comfortable access to the parapedicular pathologic lesion.

In this study, there were no statistical differences in improvements in average VAS-back pain scores, VAS-leg pain scores, JOA scores and SF-36 between PELD group and fenestration group except that VAS-back pain in PELD group was less than in fenestration group at 1 week after surgery. Also, ambulation of patients was earlier in PELD group. This may be because the patients in PELD group experienced less damage to bone tissue and paravertebral 


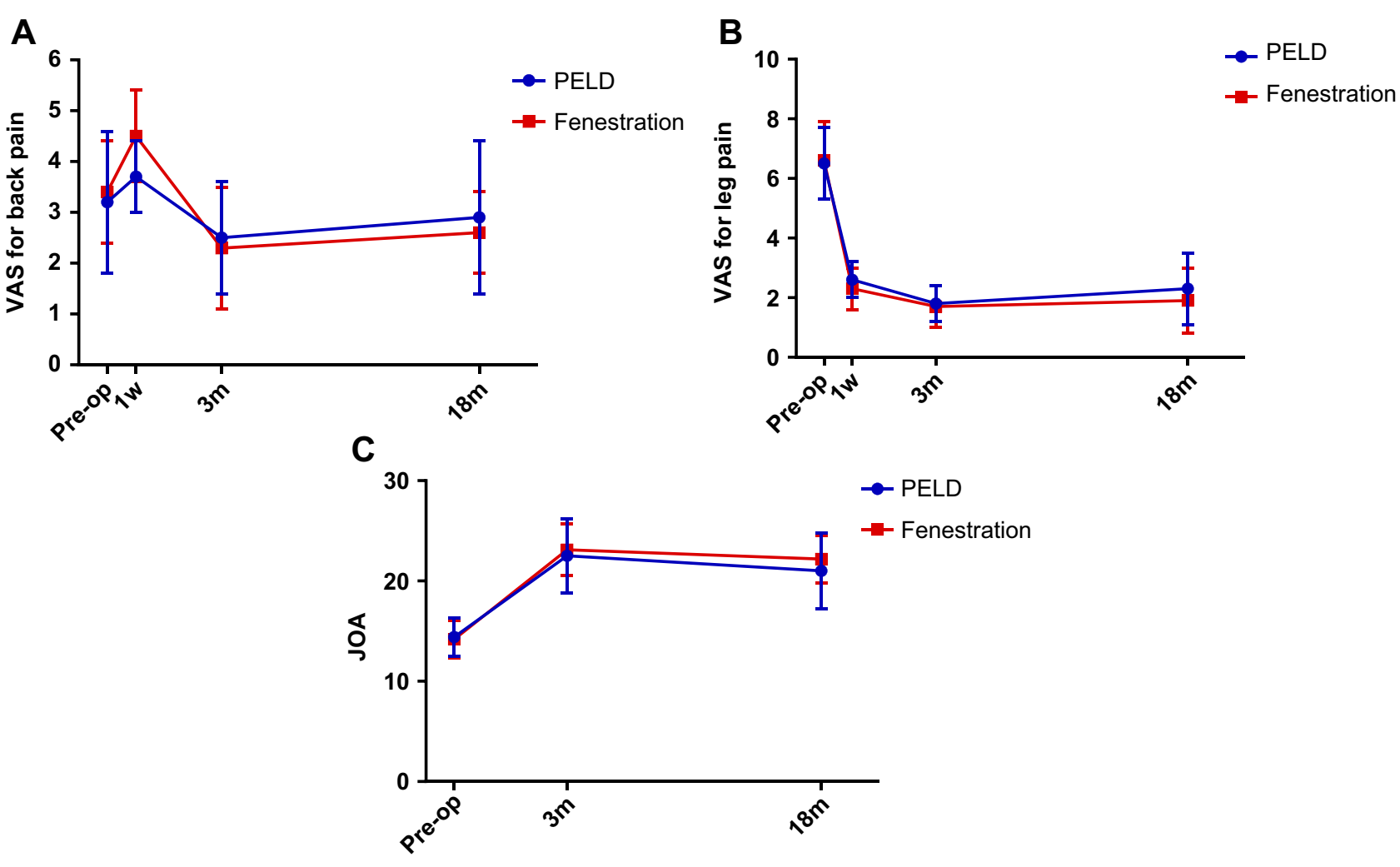

Figure I Clinical outcomes before and after endoscopic decompression at different follow-up time points in PELD group and fenestration group. (A) Visual analog scale (VAS) scores for back pain. (B) VAS scores for leg pain. (C) Japanese Orthopaedic Association Score (JOA) scores.

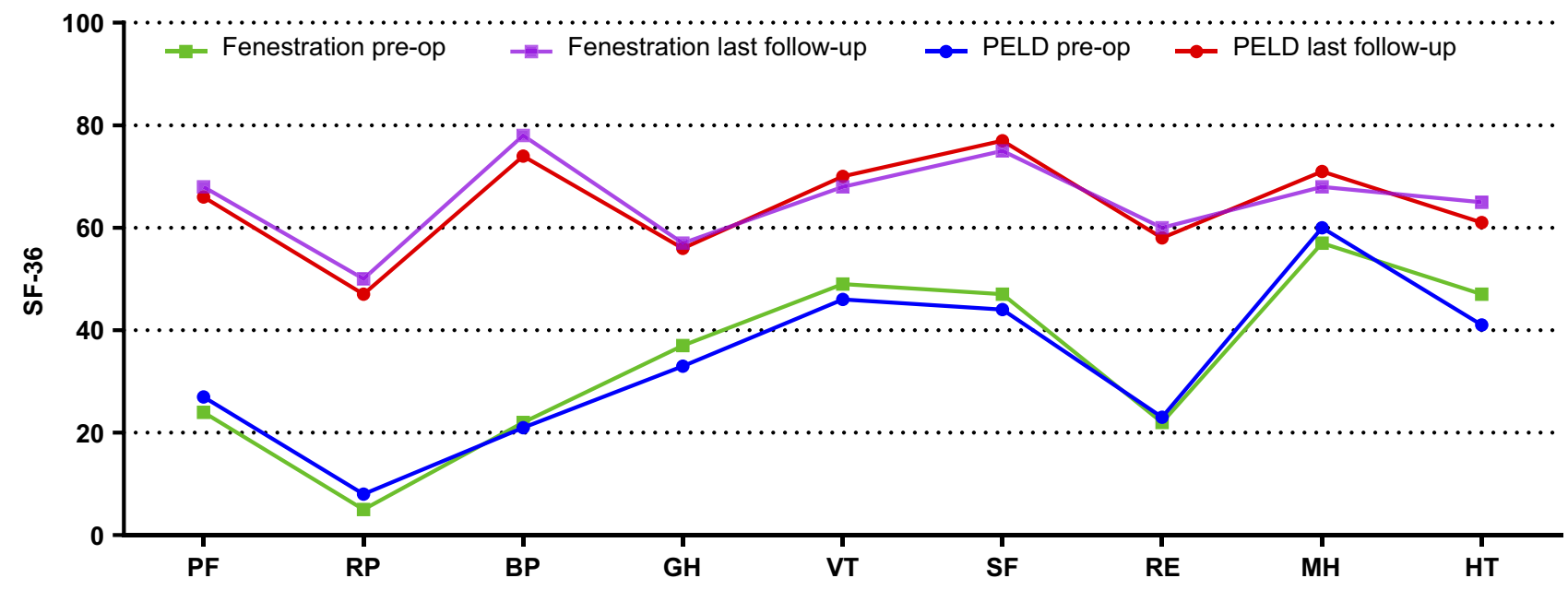

Figure 2 Outcomes of 36-Item Short-Form Health Survey (SF-36) before and at the final follow-up.

Abbreviations: PF, physical functioning; RP, role-physical; BP, bodily pain; GH, general health; VT, vitality; SF, social functioning; RE, role emotional; MH, mental health; HT, health transitions.

muscles. Furthermore, the clinical results in our study are comparable to those of other published studies of open decompression surgery patients (Table 3 ). ${ }^{22-26}$

For PELD, the foraminal area was identified on the posterior-anterior image under the guidance of the fluoroscopic $\mathrm{C}$-arm. By using trephine and an endoscopic drill, the surgeon can quickly cut off the partial hypertrophied SAP and osteophytes using video monitors which can provide clear surgical field through continuous irrigation. Since elderly patients usually have a more complicated pathological structure due to the long clinical course and scar adhesion, the operator should be careful in operative procedure, avoiding any 
A

Modified Macnab criteria in fenestration group

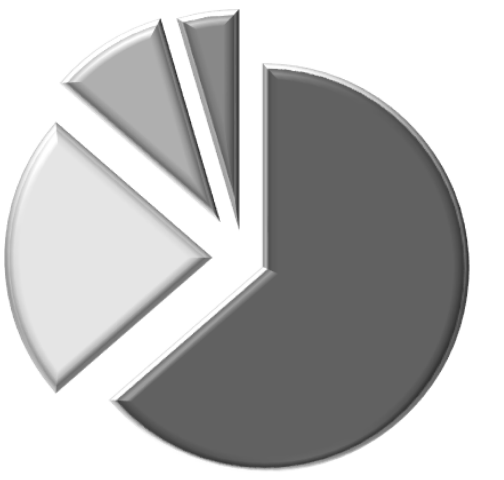

B

Modified Macnab criteria in PELD group

Ir Excellent

$\Delta \operatorname{good}$

四 fair

四 poor

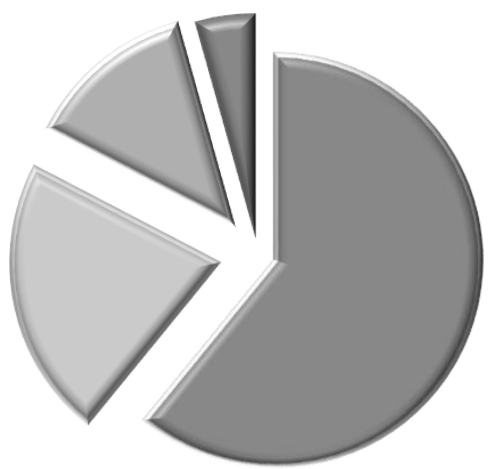

四 Excellent

1 good

四 fair

poor

Figure 3 Satisfaction rates according to the modified Macnab criteria in PELD group (A) and fenestration group (B) at the final review (I8 months) post-surgery.

A

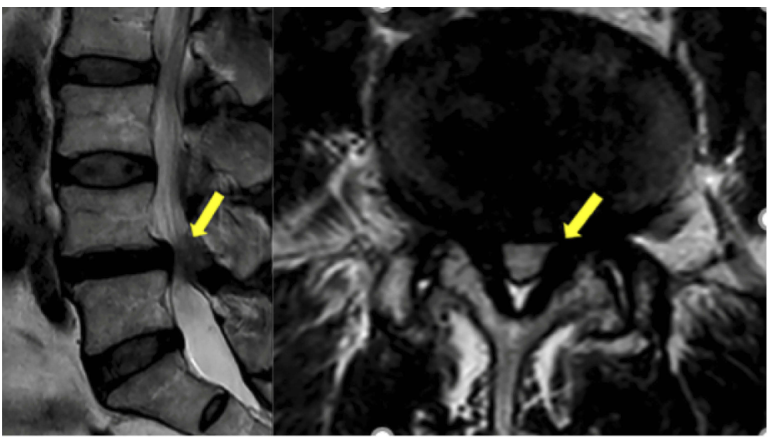

B

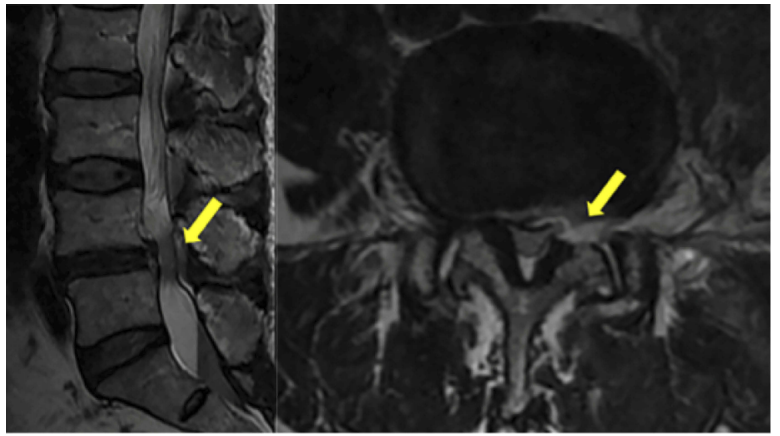

Figure 4 An $8 \mathrm{I}$-year-old female patient with lumbar lateral recess stenosis (LRS) who received PELD. (A) Preoperative magnetic resonance images (MRI) showing severe lateral recess stenosis with LRS at the left L4-5 level (yellow arrowhead). (B) Postoperative MRI showing a thorough nerve decompression (yellow arrowhead).

damage to nerve root or cauda equina. In the current study, there were no other procedure-related complications except 1 case of small dural tear in PELD group.

The biggest advantage of PELD over other operations for elderly patients is that it can be performed under local anesthesia. For the elderly patient, the age-related changes in homeostatic mechanisms alter both the pharmacokinetics and pharmacodynamics inside patients' system, $^{27}$ which increases patients' sensitivity to anesthetics and predispose patients to postoperative delirium (POD) and postoperative
A

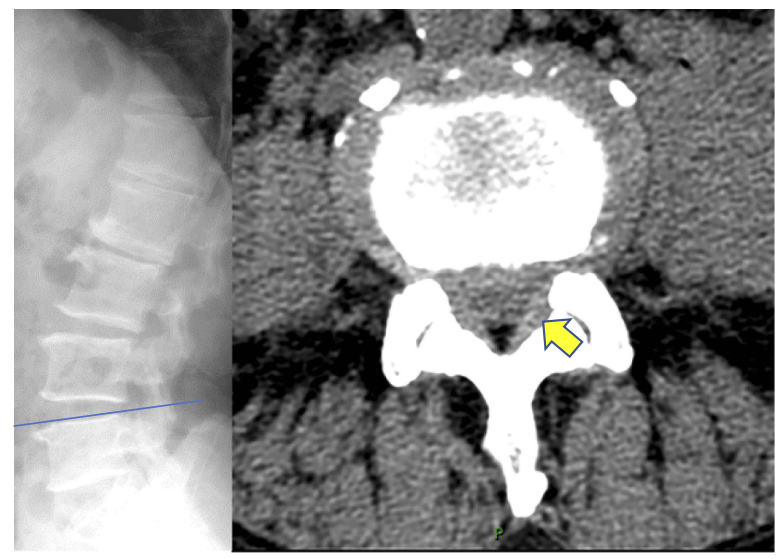

B

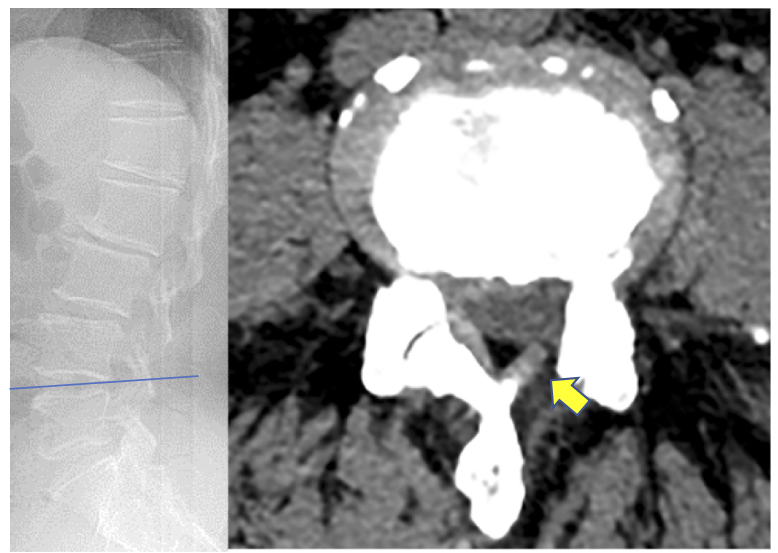

Figure 5 A 76-year-old male patient with lumbar lateral recess stenosis (LRS) who received fenestration. (A) Preoperative computed tomography (CT) images showing severe lateral recess stenosis with LRS at the left L4-5 level (yellow arrowhead). (B) Postoperative CT images showing a thorough nerve decompression (yellow arrowhead).

cognitive dysfunction (POCD) ${ }^{28}$ However, with the development of anesthesiology and improvement of surgical devices, one thing should be pointed out, that is, the vast majority of elderly patients without significant morbidity could withstand laminectomy or laminotomy and expect a clinically 
Table 3 Comparison of Clinical Results in PELD Group and Fenestration Group with Other Conventional Open Decompression Surgery for Lumbar Stenosis

\begin{tabular}{|c|c|c|c|c|c|c|}
\hline Ref & $\begin{array}{l}\text { Year of } \\
\text { Publication }\end{array}$ & $\begin{array}{l}\text { No./Av. Age } \\
\text { of Patients }\end{array}$ & $\begin{array}{l}\text { Av. } \\
\text { Follow- } \\
\text { Up } \\
\text { Period }\end{array}$ & $\begin{array}{l}\text { Success/ } \\
\text { Satisfaction } \\
\text { Rate }\end{array}$ & $\begin{array}{l}\text { Revision } \\
\text { Surgery }\end{array}$ & Complications \\
\hline Shabat $\mathrm{S}$ et $\mathrm{al}^{22}$ & 2008 & $\begin{array}{l}39 / 83.95 \text { years } \\
\text { (range } 80-91 \text { ) }\end{array}$ & $\begin{array}{l}36.8 \\
\text { months }\end{array}$ & $76 \%$ & $4 \%(1)$ & $\begin{array}{l}6 \text { urinary retention; } 5 \text { UTI; } 3 \\
\text { bronchospasm; } 2 \text { delirium; } 2 \text { wound } \\
\text { infection; } 2 \text { PAF; } 2 \text { depression; I CVA }\end{array}$ \\
\hline Ragab AA et al $^{23}$ & 2003 & $\begin{array}{l}\text { I I8/74 years } \\
\text { (range } 70-10 I)\end{array}$ & 7 years & $92.4 \%$ & $5.1 \%(6)$ & $\begin{array}{l}8 \text { dural tears; } 5 \text { confusion; } 4 \text { hypotension; I } \\
\text { dehiscence } 2 \text { urinary retention; I ileus } \\
2 \text { wound infection; I pseudogout }\end{array}$ \\
\hline Jolles BM et $\mathrm{al}^{24}$ & 2001 & $\begin{array}{l}77 / 61 \text { years } \\
\text { (range } 25-85 \text { ) }\end{array}$ & $\begin{array}{l}6.5 \\
\text { years }\end{array}$ & $79 \%$ & Unreported & $\begin{array}{l}6 \text { increased motor deficits; } 2 \text { increased } \\
\text { sensory deficits; } \\
\text { sphincter disturbance; I dural leak; I } \\
\text { superficial wound infection }\end{array}$ \\
\hline Cornefjord $M$ et $\mathrm{al}^{25}$ & 2000 & $\begin{array}{l}\text { I24/64.4 years } \\
\text { (range } 29-87 \text { ) }\end{array}$ & $\begin{array}{l}7.1 \\
\text { years }\end{array}$ & $65 \%$ & $3.5 \%(3)$ & $\begin{array}{l}\text { I cauda equina syndrome I instability; } 2 \\
\text { dural tears; } 4 \text { wound infections }\end{array}$ \\
\hline Sanderson PL et $\mathrm{al}^{26}$ & 1993 & $\begin{array}{l}34 / 72.2 \text { years } \\
\text { (range } 65-81)\end{array}$ & $\begin{array}{l}3.5 \\
\text { years }\end{array}$ & $81 \%$ & Unreported & 3 deep venous thromboses; I confusion \\
\hline Current study PELD & & $\begin{array}{l}\text { 23/82.7 years } \\
\text { (range } 75-93)\end{array}$ & $\begin{array}{l}18 \\
\text { months }\end{array}$ & $82.6 \%$ & $0 \%$ & I dural tear \\
\hline $\begin{array}{l}\text { Current study } \\
\text { Fenestration }\end{array}$ & & $\begin{array}{l}\text { 22/79.I years } \\
\text { (range } 75-88 \text { ). }\end{array}$ & $\begin{array}{l}18 \\
\text { months }\end{array}$ & $86.4 \%$ & $0 \%$ & I dural tear; 2 postoperative delirium \\
\hline
\end{tabular}

Abbreviation: UTI, urinary tract infections; CVA, cerebrovascular accident; PAF, paroxysmal atrial fibrillation.

meaningful improvement. ${ }^{29,30}$ Therefore, we believe that the method of operation should be decided on individually in each case and determined by both patients and surgeons. Accordingly, PELD is just an alternative to the conventional approach.

In the present study, we compared the outcome of PELD and fenestration for lumbar lateral recess stenosis in geriatric patients over 75 years of age. Carefully selected patients obtained good clinical results from both groups during the 18 months follow-up. Reoperation due to recurrent symptoms that suggested insufficient decompression or emerging loaddependent back pain that indicated postoperative instability was not required in either group. At the same time, there are still some limitations in this study: first, although PELD demonstrated short-term potential, long-term follow-up is needed to confirm the long-term efficacy. Second, the sample included in this study was small, owing to the relatively strict inclusion criteria. Third, we have no data of standing fulllength spine radiographs as the sagittal spinal alignment affected the outcome of patients undergoing decompression surgery for lumbar canal stenosis.

\section{Conclusion}

Both PELD and fenestration showed favorable clinical outcomes for the treatment of lumbar lateral recess stenosis in elderly patients. In terms of clinical effect and complications after operation, PELD procedure under local anesthesia can be considered as a supplement to conventional decompression surgery, especially for elderly patients with comorbidities. Attention should be paid to long-term biomechanical changes and clinical results after PELD.

\section{Acknowledgment}

This study was supported by Incubating Progam for Clinical Research and Innovation Of Renji Hospital (PYIV-17-002), the National Natural Science Foundation of China (81772292) and by Medico-Engineering cooperation Fund of Shanghai Jiao Tong University (No. YG2016MS54).

\section{Disclosure}

Zhengdong Lv, Linyu Jin and Kun Wang are co-first authors. Dr. Lifeng Lao received funding of the Shanghai 
Science and Technology Fund (17411964200), Incubating Program for Clinical Research and Innovation of Renji Hospital (PYXJS16-006) for this study. The authors report no other conflicts of interest in this work.

\section{References}

1. Lurie J, Tomkins-Lane C. Management of lumbar spinal stenosis. BMJ. 2016;352:h6234. doi:10.1136/bmj.h6234

2. Katz JN, Stucki G, Lipson SJ, et al. Predictors of surgical outcome in degenerative lumbar spinal stenosis. Spine (Phila Pa 1976). 1999;24 (21):2229-2233. doi:10.1097/00007632-199911010-00010

3. Shamji MF, Mroz T, Hsu W, et al. Management of degenerative lumbar spinal stenosis in the elderly. Neurosurgery. 2015;77(Suppl 4):S68-S74. doi:10.1227/NEU.0000000000000943

4. Otani K, Kikuchi S, Yabuki S, et al. Lumbar spinal stenosis has a negative impact on quality of life compared with other comorbidities: an epidemiological cross-sectional study of 1862 community-dwelling individuals. ScientificWorldJournal. 2013;2013:590652. doi:10.1155/2013/590652

5. Minamide A, Yoshida M, Maio K. The natural clinical course of lumbar spinal stenosis: a longitudinal cohort study over a minimum of 10 years. J Orthop Sci. 2013;18(5):693-698. doi:10.1007/s00776013-0435-9

6. Kalff R, Ewald C, Waschke A, et al. Degenerative lumbar spinal stenosis in older people: current treatment options. Dtsch Arztebl Int. 2013;110(37):613-623; quiz 624. doi:10.3238/arztebl.2013.0613

7. Deyo RA, Mirza SK, Martin BI, et al. Trends, major medical complications, and charges associated with surgery for lumbar spinal stenosis in older adults. JAMA. 2010;303(13):1259-1265. doi:10.1001/jama.2010.338

8. Getty CJ, Johnson JR, Kirwan EO, et al. Partial undercutting facetectomy for bony entrapment of the lumbar nerve root. J Bone Joint Surg Br. 1981;63-b(3):330-335. doi:10.1302/0301-620X.63B3.7263743

9. Guiot BH, Khoo LT, Fessler RG. A minimally invasive technique for decompression of the lumbar spine. Spine (Phila Pa 1976). 2002;27 (4):432-438. doi:10.1097/00007632-200202150-00021

10. Khoo LT, Fessler RG. Microendoscopic decompressive laminotomy for the treatment of lumbar stenosis. Neurosurgery. 2002;51(5 Suppl): S146-S154. doi:10.1097/00006123-200211002-00020

11. Kleeman TJ, Hiscoe AC, Berg EE. Patient outcomes after minimally destabilizing lumbar stenosis decompression: the "Port-Hole" technique. Spine (Phila Pa 1976). 2000;25(7):865-870. doi:10.1097/ 00007632-200004010-00016

12. Thome C, Borm W, Meyer F. Degenerative lumbar spinal stenosis: current strategies in diagnosis and treatment. Dtsch Arztebl Int. 2008;105(20):373-379. doi:10.3238/arztebl.2008.0373

13. Wang Y, Dou Q, Yang J, et al. Percutaneous endoscopic lumbar decompression for lumbar lateral spinal canal stenosis: classification of lateral region of lumbar spinal canal and surgical approaches. World Neurosurg. 2018;119:e276-e283. doi:10.1016/j.wneu.2018.07.133

14. Chen X, Qin R, Hao J, et al. Percutaneous endoscopic decompression via transforaminal approach for lumbar lateral recess stenosis in geriatric patients. Int Orthop. 2019;43(5):1263-1269. doi:10.1007/ s00264-018-4051-3

Clinical Interventions in Aging

\section{Publish your work in this journal}

Clinical Interventions in Aging is an international, peer-reviewed journal focusing on evidence-based reports on the value or lack thereof of treatments intended to prevent or delay the onset of maladaptive correlates of aging in human beings. This journal is indexed on PubMed Central, MedLine, CAS, Scopus and the Elsevier
15. Li ZZ, Hou SX, Shang WL, et al. Percutaneous lumbar foraminoplasty and percutaneous endoscopic lumbar decompression for lateral recess stenosis through transforaminal approach: technique notes and 2 years follow-up. Clin Neurol Neurosurg. 2016;143:90-94. doi:10.1016/j.clineuro.2016.02.008

16. Nellensteijn J, Ostelo R, Bartels R, et al. Transforaminal endoscopic surgery for lumbar stenosis: a systematic review. Eur Spine J. 2010;19(6):879-886. doi:10.1007/s00586-009-1272-6

17. Forsth P, Olafsson G, Carlsson T, et al. A randomized, controlled trial of fusion surgery for lumbar spinal stenosis. $N$ Engl J Med. 2016;374 (15):1413-1423. doi:10.1056/NEJMoa1513721

18. Young S, Veerapen R, O'Laoire SA. Relief of lumbar canal stenosis using multilevel subarticular fenestrations as an alternative to wide laminectomy: preliminary report. Neurosurgery. 1988;23(5):628-633. doi:10.1227/00006123-198811000-00014

19. Copay AG, Glassman SD, Subach BR, et al. Minimum clinically important difference in lumbar spine surgery patients: a choice of methods using the oswestry disability index, medical outcomes study questionnaire short form 36, and pain scales. Spine J. 2008;8 (6):968-974. doi:10.1016/j.spinee.2007.11.006

20. Vital JM, Lavignolle B, Grenier N, et al. Anatomy of the lumbar radicular canal. Anat Clin. 1983;5(3):141-151. doi:10.1007/BF01798999

21. Lee CK, Rauschning W, Glenn W. Lateral lumbar spinal canal stenosis: classification, pathologic anatomy and surgical decompression. Spine (Phila Pa 1976). 1988;13(3):313-320. doi:10.1097/00007632-19880 3000-00015

22. Shabat S, Arinzon Z, Folman Y, et al. Long-term outcome of decompressive surgery for lumbar spinal stenosis in octogenarians. Eur Spine J. 2008;17(2):193-198. doi:10.1007/s00586-007-0514-8

23. Ragab AA, Fye MA, Bohlman HH. Surgery of the lumbar spine for spinal stenosis in 118 patients 70 years of age or older. Spine (Phila Pa 1976). 2003;28(4):348-353. doi:10.1097/01.BRS.0000048494.66599.DF

24. Jolles BM, Porchet F, Theumann N. Surgical treatment of lumbar spinal stenosis. Five-year follow-up. J Bone Joint Surg Br. 2001;83 (7):949-953. doi:10.1302/0301-620X.83B7.0830949

25. Cornefjord M, Byrod G, Brisby H, et al. A long-term (4- to 12-year) follow-up study of surgical treatment of lumbar spinal stenosis. Eur Spine J. 2000;9(6):563-570. doi:10.1007/s005860000161

26. Sanderson PL, Wood PL. Surgery for lumbar spinal stenosis in old people. J Bone Joint Surg Br. 1993;75(3):393-397. doi:10.1302/ 0301-620X.75B3.8496206

27. Hazen SE, Larsen PD, Martin JL. General anesthesia and elderly surgical patients. AORN J. 1997;65(4):815-819, 821-812. doi:10.1016/S00012092(06)63005-6

28. Strom C, Rasmussen LS, Sieber FE. Should general anaesthesia be avoided in the elderly? Anaesthesia. 2014;69 Suppl 1:35-44. doi:10.1111/anae.12493

29. Ulrich NH, Kleinstuck F, Woernle CM, et al. Clinical outcome in lumbar decompression surgery for spinal canal stenosis in the aged population: a prospective Swiss multicenter cohort study. Spine (Phila Pa 1976). 2015;40(6):415-422. doi:10.1097/BRS.0000000000000765

30. Galiano K, Obwegeser AA, Gabl MV, et al. Long-term outcome of laminectomy for spinal stenosis in octogenarians. Spine (Phila Pa 1976). 2005;30(3):332-335. doi:10.1097/01.brs.0000152381.20719.50

Bibliographic databases. The manuscript management system is completely online and includes a very quick and fair peer-review system, which is all easy to use. Visit http://www.dovepress.com testimonials.php to read real quotes from published authors. 